\title{
Proteomics based markers of clinical pain severity in juvenile idiopathic arthritis
}

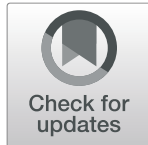

Hanne Van Der Heijden ${ }^{1,2,3 \dagger}$, Benoit Fatou ${ }^{4 \dagger}$, Diana Sibai ${ }^{1}$, Kacie Hoyt $^{5}$, Maria Taylor ${ }^{5}$, Kin Cheung ${ }^{6}$, Jordan Lemme ${ }^{1}$, Mariesa Cay ${ }^{1}$, Benjamin Goodlett', Jeffery Lo ${ }^{5}$, Melissa M. Hazen ${ }^{5}$, Olha Halyabar ${ }^{5}$, Esra Meidan ${ }^{5}$, Rudy Schreiber², Camilo Jaimes $^{8}$, Kirsten Ecklund ${ }^{8}$, Lauren A. Henderson ${ }^{5}$, Margaret H. Chang ${ }^{5}$, Peter A. Nigrovic ${ }^{5}$, Robert P. Sundel ${ }^{5}$, Hanno Steen ${ }^{4,9,10^{*}}$ and Jaymin Upadhyay ${ }^{1,11^{*}}$ (D)

\begin{abstract}
Introduction: Juvenile idiopathic arthritis $(J \mid A)$ is a cluster of autoimmune rheumatic diseases occurring in children 16 years of age or less. While it is well-known that pain may be experienced during inflammatory and noninflammatory states, much remains ambiguous regarding the molecular mechanisms that may drive JIA pain. Thus, in this pilot study, we explored the variability of the serum proteomes in relation to pain severity in a cohort of JIA patients.

Methods: Serum samples from $15 \mathrm{JIA}$ patients (male and female, $12.7 \pm 2.8$ years of age) were assessed using liquid chromatography/mass spectrometry (LC/MS). Correlation analyses were performed to determine the relationships among protein levels and self-reported clinical pain severity. Additionally, how the expression of pain-associated proteins related to markers of inflammation (Erythrocyte Sedimentation Rate (ESR)) or morphological properties of the central nervous system (subcortical volume and cortical thickness) implicated in JIA were also evaluated.

Results: 306 proteins were identified in the JIA cohort of which 14 were significantly $(p<0.05)$ associated with clinical pain severity. Functional properties of the identified pain-associated proteins included but were not limited to humoral immunity (IGLV3.9), inflammatory response (PRG4) and angiogenesis (ANG). Associations among painassociated proteins and ESR (IGHV3.9, PRG4, CST3, VWF, ALB), as well as caudate nucleus volume (BTD, AGT, IGHV3.74) and insular cortex thickness (BTD, LGALS3BP) were also observed.
\end{abstract}

Conclusions: The current proteomic findings suggest both inflammatory- and non-inflammatory mediated mechanisms as potential factors associated with JIA pain. Validation of these preliminary observations using larger patient cohorts and a longitudinal study design may further point to novel serologic markers of pain in JIA.

\footnotetext{
* Correspondence: hanno.steen@childrens.harvard.edu;

jaymin.upadhyay@childrens.harvard.edu

${ }^{\dagger}$ Hanne Van Der Heijden and Benoit Fatou contributed equally to this work.

${ }^{4}$ Department of Pathology, Boston Children's Hospital, Harvard Medical

School, Boston, MA, USA

'Department of Anesthesiology, Critical Care and Pain Medicine, Boston

Children's Hospital, Harvard Medical School, Boston, MA, USA

Full list of author information is available at the end of the article
}

C C The Author(s). 2022 Open Access This article is licensed under a Creative Commons Attribution 4.0 International License, which permits use, sharing, adaptation, distribution and reproduction in any medium or format, as long as you give appropriate credit to the original author(s) and the source, provide a link to the Creative Commons licence, and indicate if changes were made. The images or other third party material in this article are included in the article's Creative Commons licence, unless indicated otherwise in a credit line to the material. If material is not included in the article's Creative Commons licence and your intended use is not permitted by statutory regulation or exceeds the permitted use, you will need to obtain permission directly from the copyright holder. To view a copy of this licence, visit http://creativecommons.org/licenses/by/4.0/. The Creative Commons Public Domain Dedication waiver (http://creativecommons.org/publicdomain/zero/1.0/) applies to the data made available in this article, unless otherwise stated in a credit line to the data. 


\begin{abstract}
Highlights
In the current preliminary study, serum proteins associated with pain severity were identified in JIA patients. Pain-associated proteins had functional roles predominantly in immune or inflammatory processes.

Correlations of pain-associated proteins with ESR and altered CNS morphology were also observed with ESR and altered CNS morphology were also observed.

Larger-scale as well as longitudinal studies are needed to determine if evaluation of the proteome may provide a platform for identifying novel analgesic targets in JIA.
\end{abstract}

Keywords: Proteomics, Mass spectrometry, Juvenile idiopathic arthritis, Pain, Inflammation

\section{Introduction}

Juvenile idiopathic arthritis (JIA) is a common childhood rheumatic illness categorized into seven subtypes and characterized by musculoskeletal joint pathology present for greater than 6 weeks $[1,2]$. One of the most frequently occurring and debilitating symptoms of JIA is pain $[3,4]$, significantly impacting quality of life [5]. Pain in JIA appears to have multifactorial causes and can be driven by varying mechanisms [6]. Pain, particularly when induced by inflammation, may be ameliorated by pharmacological approaches such as disease modifying anti-rheumatic drugs (DMARDs) and biologics (e.g., tumor necrosis factor (TNF)- $\alpha$ inhibitors). Nonpharmacological modalities, including exercise or cognitive behavioral therapy, also may be prescribed in parallel [4, 7-13]. Notwithstanding the availability of these therapeutic options, mitigating pain in JIA remains challenging, which may in part stem from unknown, noninflammatory pain processes that are active in some JIA patients.Cytokine products secreted by macrophages and $\mathrm{T}$ cells due to an activated immune system, are considered to mediate a chronic inflammatory status and joint pathology in JIA $[14,15]$. For example, levels of interleukin (IL) 18 in serum and synovial fluid of JIA patients have been identified as marker of disease severity, and TNF- $\alpha$, macrophage inhibitory factor (MIF), IL-1, IL-6 and members of the $\mathrm{CC}$ chemokine family have been reported to contribute to inflammatory responses in JIA [15-17]. Moreover, several autoantibodies are currently used to distinguish JIA subtypes. Yet, no biomarkers have been validated for the purposes of guiding pain treatment in JIA populations [18]. To this end, we have embarked on a liquid-chromatography/mass spectrometry (LC/MS)-based serum proteomic approach, where protein expression in complex fluid samples is identified and accurately quantified [19-21]. A proteomic approach previously led to identification of proteins associated with ion channels, receptors and signaling pathways implicated with acute and chronic pain states [22]. Furthermore, MS has previously been utilized to decipher protein composition in cerebrospinal fluid in patients with fibromyalgia and rheumatoid arthritis (RA) [23].
Although the synovial proteome in JIA patients has been investigated in prior work [24, 25], to our knowledge, a serum proteomics approach in JIA in the context of pain has not been carried out as of now.

The aim of this preliminary study was to identify painassociated proteins in JIA to gain further insight into the biological underpinnings of pain in this rheumatic condition, which in turn may set the foundation for identifying novel therapeutic targets for pain treatment. In the current report, an LC/MS-based proteomics analysis of blood serum samples was performed to identify proteins that associate with clinical pain severity in a cohort of JIA patients. Subsequently, the association was examined between pain-associated proteins and other aspects of JIA, such as erythrocyte sedimentation rate (ESR), clinical juvenile arthritis disease activity score (cJADAS) [26], and CNS morphological properties previously implicated in JIA [27].

\section{Methods}

\section{Study participants}

Male and female JIA patients $(N=15,12.5 \pm 2.8$ years $)$ were evaluated in this study (see also Supplemental Fig. 1). This cohort was described in our prior report [27]. Patients were recruited from the Rheumatology Program at Boston Children's Hospital (BCH), following approval of the $\mathrm{BCH}$ Institutional Review Board. Written consent and assent were provided by the patients' parent or guardian and patient, respectively before participation in this investigation. Prior to blood sample collection $(2 \mathrm{~mL})$, patients completed the PROMIS ${ }^{\circ}$ Numeric Rating Scale (0-10 scale), which is a self-assessment of clinical pain over the last 7 days (PROMIS; http://www. healthmeasures.net). In this scale, 0 corresponds to no pain and 10 is the worst pain imaginable. The cJADAS, specifically the cJADAS-10, a composite disease activity score for JIA, which does not include an acute phase reactant, was determined for each patient at the time of enrollment [26]. Blood sample collection and completion of the clinical pain rating questionnaire were accomplished during the same study visit. One patient did not provide a blood sample. All 
enrolled patients were on active treatment and underwent clinical examination to determine the presence of pain and other elements of arthritis, including joint inflammation, redness, stiffness, or tenderness. Furthermore, JIA patients were also evaluated with noncontrast MRI to detect possible bone erosion, cartilage degradation, joint space narrowing, bone marrow edema, soft-tissue edema, joint fluid, synovitis, and tenosynovitis. Each musculoskeletal MRI dataset was assessed by a board-certified pediatric radiologist (Dr. Ecklund).' ESR values were available for 13 out of the 16 patients, while combined neuroimaging and musculoskeletal MRI analyses were performed as previously described in nine out of the 16 patients [27].

\section{LC/MS analysis}

A volume of $1 \mathrm{ul}$ serum was first diluted in $60 \mu \mathrm{l}$ of urea buffer $(8 \mathrm{M}$ in $50 \mathrm{mM}$ ammonium bicarbonate buffer) and then $15 \mu \mathrm{l}$ of dithiothreitol $(0.05 \mathrm{M}$ final concentration) was added and the samples were incubated $30 \mathrm{~min}$ at $800 \mathrm{rpm}$ in room temperature. A volume of $10 \mu \mathrm{l}$ of iodoacetamide was added and an incubation was performed for $30 \mathrm{~min}$ at $800 \mathrm{rpm}$ in room temperature in dark. A volume of $10 \mathrm{ul}$ of 0.05 $M$ DTT was added to quench the alkylation and the sample was incubated $15 \mathrm{~min}$ at room temperature. The samples were then transferred to SP3 beads mixture (1:10 protein to beads) [28], previously washed twice with HPLC water. A volume of 150ul of absolute ethanol was added to the sample/bead mixture before incubation at $1000 \mathrm{rpm}$ at room temperature for $10 \mathrm{~min}$. The mixture was then transferred to an automatic liquid handling robot instrument (Opentrons, NY) to wash the beads and remove the supernatant before adding $1 \mu \mathrm{g}$ of trypsin and incubating for $2 \mathrm{~h}$ at $37^{\circ} \mathrm{C}$ at $1000 \mathrm{rpm}$ on thermomixer. After trypsin digestion, the samples were centrifuged $10 \mathrm{~min}$ at $3220 \times \mathrm{g}$ before acidification using $2 \% \mathrm{v} / \mathrm{v}$ formic acid.

A discovery-based proteomic workflow was performed with no depletion nor fractionation of the serum samples using the SP3 protocol followed by LC/MS analysis in data-dependent acquisition mode. An amount of 200 ng was injected on the Evosep LC system equipped with a Pepsep column $(15 \mathrm{~cm}$ length; ID $=150 \mathrm{um})$ connected to a timsTOF pro mass spectrometer instrument (Bruker Daltonics, Billerica, MA) using the 60 samples per day. The data were searched using MSFragger software v3.1.1 using the following parameters: a maximum of three missed cleavages, oxidation of methionine residues set as variable modification and carbamidomethylation of cysteine residues set as fixed modification (other parameters were set as default).

\section{Data analysis}

The data were then searched to obtain the protein identification and quantification in all samples. RStudio software packages were utilized for all statistical analyses (https://www.rstudio.com). In the current report, our statistical analyses were focused on determining how levels of various proteins were associated with clinical pain severity, ESR, and clinical severity (as determined by cJADAS), and also, whether and how identified painassociated proteins were integrated with other elements of the JIA (i.e., inflammation, clinical severity and CNS properties) Spearman correlation coefficients were calculated to determine correlations between protein density and clinical pain severity, while Pearson's correlation coefficients were calculated to determine significant associations among continuous variables (e.g., protein levels, ESR values, and CNS morphological properties). Furthermore, as clinical pain severity is a subjective measure and clear cut off points are ill-defined, we aimed to investigate the serum proteome changes related to selfreports of pain using a more unbiased statistical approach by taking the extremes (i.e., the samples with the lowest and highest scores were sorted into two main groups generating "Low" and "High" pain JIA cohorts). Subsequently, a statistical comparison was performed using a student $\mathrm{t}$-test comparing the mean difference between the High and Low pain cohorts. The results were shown by a Volcano plot with the $\log 2$ mean difference on the $\mathrm{x}$-axis and the $-\log 10 p$-value on the $\mathrm{y}$-axis.

\section{Results}

\section{Patient overview}

Clinical pain intensity ratings of the enrolled JIA patients ranged from 0 to 8 (mean pain intensity rating: $3.00 \pm$ 2.56). Furthermore, ESR values ranged from 1 to 26 (mean ESR: $10.92 \pm 8.54$ ) and cJADAS scores were between 0 and 16 (mean score: $5.17 \pm 5.78$ ).

\section{Identification of pain-associated proteins using mass spectrometry analysis}

High throughput serum proteomics of the samples collected from 15 JIA patients identified 306 proteins. Only proteins detected in 9 or more patients were used for further analyses. Spearman's correlation analyses between protein expression and clinical pain severity scores resulted in 14 protein that showed positive $(\mathrm{r}>0.5)$ or negative $(\mathrm{r}<-0.5)$ correlations with pain levels (Table 1, Fig. 1A). Functional roles of the 14 proteins ranged from humoral immunity, angiogenesis, autoimmunity and enzymatic reactions (Table 1, Fig. 2). Additionally, protein expression was evaluated using a grouping method based on the pain scale 0,1 , and 2 to define a 'Low' pain group and 4, 6 , and 8 to define 'High' pain group (Fig. 3). This 
Table 1 Proteins vs. Clinical Pain Level. Proteins identified in serum of JIA patients demonstrating significant $(p<0.05)$ association to clinical pain levels with corresponding function. Samples sizes of $N=14^{*}$ or $N=15^{* *}$ were present for all proteins

\begin{tabular}{|c|c|c|c|c|}
\hline $\begin{array}{l}\text { Proteins } \\
\text { Related to } \\
\text { Pain }\end{array}$ & Function & $\begin{array}{l}\text { Spearman } \\
\text { Correlation } \\
\text { Coefficient }(r)\end{array}$ & $\begin{array}{l}\text { P-value } \\
\text { (two-tailed) }\end{array}$ & $\begin{array}{l}95 \% \\
\text { confidence } \\
\text { interval }\end{array}$ \\
\hline IGLV3.9* & Immunoglobulins: Humoral immunity & -0.70 & 0.007 & -0.90 to -0.25 \\
\hline IGHG4** & Immunoglobulins: Humoral immunity & -0.60 & 0.020 & -0.86 to -0.11 \\
\hline IGKV1.5** & Immunoglobulins: Humoral immunity & 0.54 & 0.040 & -0.83 to -0.023 \\
\hline IGKV3D.15** & Immunoglobulins: Humoral immunity & 0.59 & 0.024 & -0.85 to -0.091 \\
\hline IGHV3.72** & Immunoglobulins: Humoral immunity & -0.54 & 0.041 & -0.83 to -0.018 \\
\hline IGHV3.74 & Immunoglobulins: Humoral immunity & -0.72 & 0.004 & -0.902 to -0.31 \\
\hline LGALS3BP** & Promotes integrin-mediated cell adhesion: Immune response & 0.52 & 0.049 & -0.005 to 0.82 \\
\hline $\mathrm{ANG}^{* *}$ & $\begin{array}{l}\text { Role in angiogenesis and autoimmune response, suggested to play a role in } \\
\text { immune-mediated inflammatory response }\end{array}$ & -0.53 & 0.046 & -0.82 to -0.002 \\
\hline PRG4** & $\begin{array}{l}\text { Role in boundary lubrication within articulating joints, involved in vesicle- } \\
\text { mediated transport in immune responses }\end{array}$ & 0.65 & 0.011 & 0.183 to 0.874 \\
\hline $\mathrm{CST}^{*}$ & $\begin{array}{l}\text { Cystatin C: Inhibition of cysteine proteases, involved in inflammation and immune } \\
\text { regulation, vascular remodeling and cell migration }\end{array}$ & -0.58 & 0.033 & -0.85 to -0.050 \\
\hline$W W F^{* *}$ & Hemostasis, thrombosis and vascular inflammation & -0.55 & 0.035 & -0.84 to -0.038 \\
\hline $\mathrm{ALB}^{* *}$ & Regulate osmotic pressure & 0.57 & 0.028 & -0.84 to -0.067 \\
\hline $\mathrm{AGT}^{* *}$ & Angiotensinogen: Blood pressure and fluid and salt regulation & 0.55 & 0.035 & 0.041 to 0.84 \\
\hline BTD** & Enzyme biotinidase: Biotin removal from food & 0.53 & 0.045 & 0.005 to 0.824 \\
\hline
\end{tabular}

grouping for 'Low' and 'High' demonstrated a number of 12 differentially expressed proteins (DEPs; $p<$ $0.05)$.

\section{Relationship between pain-associated proteins and ESR values and CJADAS scores}

Amongst all 306 proteins identified in the serum of JIA patients, various proteins were associated with ESR (Fig. 1B, see also Supplemental Fig. 1). Table 2 denotes the level of association among Pain-associated proteins and ESR levels. IGLV3.9, PRG4, CST3, VWF and ALB in particular showed significant correlation with ESR with most proteins having roles in immunemediated responses in addition to other cellular functions (e.g., vascular remodeling and cell migration (CST3) or boundary lubrication within articulating joints (PRG4)). Significant correlation between cJADAS scores and protein levels were found for IGHV6-1 $(\mathrm{r}=-0.64, P=0.014)$, IGHV2-70 $(\mathrm{r}=0.58$, $P=0.05)$, IGHD $(\mathrm{r}=0.60, P=0.023)$, and IGLC3 $(\mathrm{r}=$ $0.57, P=0.03$ ) (Fig. $1 \mathrm{C}$ ), which were primarily related
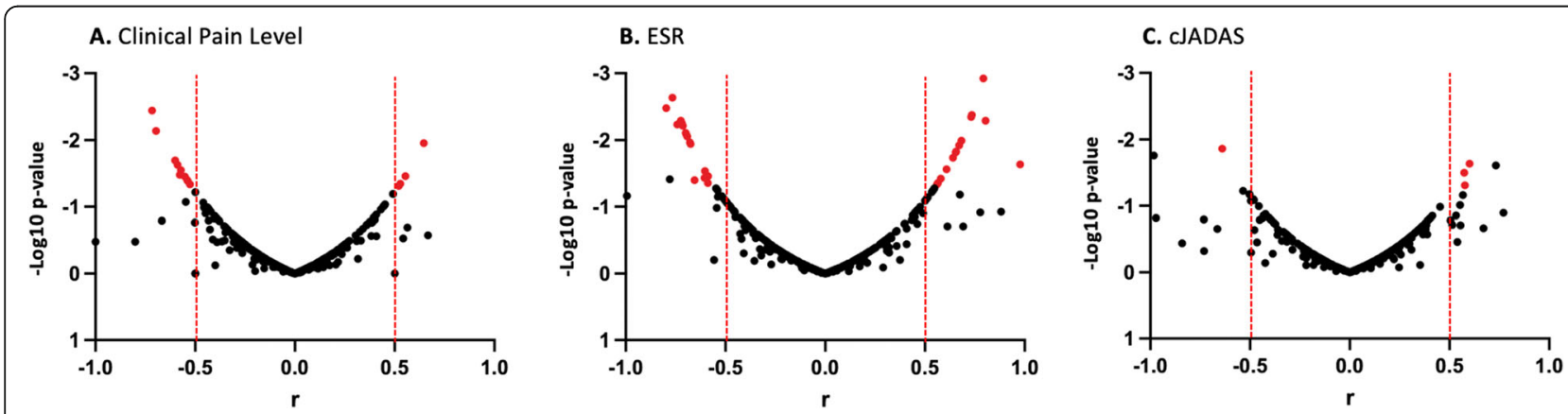

Fig. 1 Correlation Between Protein Expression and Clinical Benchmarks. Volcano plots of protein intensity correlation to (A) pain severity, (B) erythrocyte sedimentation rate (ESR) values and (C) clinical juvenile disease activity score (CJADAS). Significantly $(p<0.05)$ correlated proteins are plotted in red. Proteins passing an $r$ value of 0.5 , but not significant due to the small number of data points are shown in black. Further details on proteins significantly correlating with clinical pain levels are provided in Table 1 



to humoral immunity [29]. These correlation values listed above were derived based on 14 data points. A significant association between Pain-associated proteins and cJADAS scores were absent throughout all Pain-associated proteins (Table 2).

\section{Relationship between pain-associated proteins and central morphological properties}

Our recent investigation utilizing the same JIA patient sample identified a significant association between caudate volume and clinical pain intensity ratings as well as a significant correlation between cortical thickness of the insula cortex and ESR values [27]. Therefore, the relationship, or lack thereof, between Pain-associated proteins described above and morphological properties of the caudate nucleus and insula were explored.

The left hemisphere caudate nucleus volume was not significantly correlated with any of the Pain-associated proteins (Table 3). The right hemisphere caudate nucleus volume negatively correlated with BTD and AGT, while positively correlated with IGHV3.74. The left insular cortical thickness was not significantly correlated to any of the Pain-associated proteins. However, significant $(P=0.05)$ associations were revealed between right 
Table 2 Pain-associated Proteins vs. ESR and cJADAS. Pain protein (see Table 1) correlation with erythrocyte sedimentation rate (ESR) and clinical juvenile disease activity score (cJADAS) in JIA patients. Correlation ( $r$ ) and P-values (two-tailed) are displayed. Sample sizes (N) are denoted for each correlation analyses

\begin{tabular}{lll}
\hline Pain Proteins & Correlation with ESR $(\boldsymbol{N}=\mathbf{1 3})$ & Correlation with cJADAS (N=14) \\
\hline IGLV3.9 & $\mathbf{r}=-\mathbf{0 . 5 9 ,} \boldsymbol{P}=\mathbf{0 . 0 4}$ & $r=-0.34, P=0.26(N=13)$ \\
IGHG4 & $r=-0.10, P=0.76$ & $r=-0.49, P=0.079$ \\
IGKV1.5 & $r=-0.27, P=0.37$ & $r=-0.16, P=0.60$ \\
IGKV3D.15 & $r=0.001, P=0.99$ & $r=0.011, P=0.97$ \\
IGHV3.72 & $r=-0.49, P=0.09$ & $r=0.12, P=0.685$ \\
IGHV3.74 & $r=-0.30, P=0.31$ & $r=-0.02, P=0.95$ \\
LGALS3BP & $r=0.20, P=0.51$ & $r=0.31, P=0.28$ \\
ANG & $r=0.02, P=0.95$ & $r=-0.36, P=0.21$ \\
PRG4 & $\mathbf{r}=\mathbf{0 . 6 5 , P = 0 . 0 2}$ & $r=-0.27, P=0.35$ \\
CST3 & $\mathbf{r}=-\mathbf{0 . 7 4 , P = 0 . 0 1}$ & $r=-0.18, P=0.56(N=13)$ \\
WWF & $\mathbf{r}=-\mathbf{0 . 7 2 , P = 0 . 0 1}$ & $r=0.10, P=0.73$ \\
ALB & $\mathbf{r}=-\mathbf{0 . 7 0 , P = 0 . 0 1}$ & $r=0.09, P=0.75$ \\
AGT & $r=0.16, P=0.59$ & $r=-0.02, P=0.95$ \\
BTD & $r=0.13, P=0.66$ & $r=0.05, P=0.86$ \\
\hline
\end{tabular}

insular thickness values and two of the Pain-associated proteins (BTD and LGALS3BP).

\section{Discussion}

There is a clear need for a deeper understanding of the complex mechanisms that underlie pain in JIA and other rheumatic conditions impacting pediatric populations. The current study revealed a number of Pain-associated proteins by characterizing the serum proteome derived from JIA patients. The identified proteins ranged in their biological functions from humoral immunity, angiogenesis, autoimmunity and enzymatic reactions. Furthermore, these preliminary results further suggest the close interactions between immune and nervous systems, and the critical role immune cells and their mediators play in regulating acute and chronic pain states [30].

Many of the identified Pain-associated proteins are involved in immune processes. LGALS3BP is a heavily

Table 3 Pain-associated Proteins vs. Central Morphological Properties. Pain protein (see Table 1) correlation with caudate nucleus volume and insular thickness values in JIA patients. Pearson correlation $r$ values and corresponding P-values (two-tailed) are displayed. Sample size is indicated for each correlation pair

\begin{tabular}{|c|c|c|c|c|}
\hline $\begin{array}{l}\text { Pain } \\
\text { Proteins }\end{array}$ & $\begin{array}{l}\text { Left Caudate Nucleus Volume } \\
(N=9)\end{array}$ & $\begin{array}{l}\text { Right Caudate Nucleus Volume } \\
(N=9)\end{array}$ & $\begin{array}{l}\text { Left Insular Thickness } \\
(N=9)\end{array}$ & $\begin{array}{l}\text { Right Insular Thickness } \\
(N=9)\end{array}$ \\
\hline$\overline{\text { IGLV3.9 }}$ & $r=0.56, P=0.12$ & $r=0.64, P=0.06$ & $r=0.11, P=0.77$ & $r=0.54, P=0.14$ \\
\hline IGHG4 & $r=0.41, P=0.27$ & $r=0.30, P=0.43$ & $r=0.05, P=0.90$ & $r=0.11, P=0.77$ \\
\hline IGKV1.5 & $r=0.13, P=0.75$ & $r=0.27, P=0.49$ & $r=0.27, P=0.48$ & $r=0.43, P=0.24$ \\
\hline IGKV3D.15 & $r=0.58, P=0.10$ & $r=0.64, P=0.06$ & $r=-0.25, P=0.51$ & $r=0.31, P=0.42$ \\
\hline IGHV3.72 & $r=0.41, P=0.28$ & $r=0.435, P=0.242$ & $r=0.15, P=0.70$ & $r=0.14, P=0.72$ \\
\hline IGHV3.74 & $r=0.63, P=0.07$ & $r=0.70, P=0.04$ & $r=-0.13, P=0.73$ & $r=0.52, P=0.15$ \\
\hline LGALS3BP & $r=-0.63, P=0.07$ & $r=-0.64, P=0.07$ & $r=-0.61, P=0.09$ & $r=-0.75, P=0.02$ \\
\hline ANG & $r=0.44, P=0.24$ & $r=0.44, P=0.23$ & $r=0.47, P=0.19$ & $r=0.54, P=0.14$ \\
\hline PRG4 & $r=-0.53, P=0.14$ & $r=-0.52, P=0.15$ & $r=-0.25, P=0.51$ & $r=-0.24, P=0.53$ \\
\hline CST3 & $r=-0.02, P=0.95$ & $r=0.03, P=0.95$ & $r=0.65, P=0.06$ & $r=0.28, P=0.47$ \\
\hline WF & $r=0.30 P=0.43$ & $r=0.33, P=0.39$ & $r=0.36, P=0.34$ & $r=0.17, P=0.67$ \\
\hline ALB & $r=0.57, P=0.11$ & $r=0.62, P=0.07$ & $r=0.13, P=0.74$ & $r=0.26, P=0.50$ \\
\hline BTD & $r=-0.67, P=0.051$ & $r=-0.78, P=0.01$ & $r=-0.17, P=0.66$ & $r=-0.69, P=0.04$ \\
\hline AGT & $r=-0.61, P=0.082$ & $r=-0.73, P=0.03$ & $r=0.15, P=0.70$ & $r=-0.45, P=0.22$ \\
\hline
\end{tabular}


glycosylated secreted molecule with an immunoinhibitory function [31] often found to be upregulated in cancer, but has also been implicated in various other diseases (e.g., RA) [32]. Furthermore, the subvariants IGLV3.9, IGHG4, IGKV1.5, IGKV3D.15, IGHV3.72 and IGHV3.74 are all members of the immunoglobulin family, binding to particular antigens as part of the immune response, but specific targets of these immunoglobulins are unknown [33]. The identification of immunoglobulins whose abundance levels show positive correlations with pain severity is consistent with current experimental therapies, as clinical trials on binding immunoglobulin protein (BiP), targeting immunoglobulins, have been performed for treatment of RA [34]. Amongst an abundance of processes, CST3 is also considered to be involved with immune responses [35]. ANG, or angiogenin, is most often implicated in tumor-associated angiogenesis, but has been suggested to inhibit inflammatory processes $[36,37]$ and to mediate local inflammation in arthritis [38]. Moreover, VWF is thought to reflect vascular damage and thrombosis [39]. Lastly, PRG4 has been shown to play a protective factor within articular joints [40], but its role in mediating antiinflammatory processes has also been confirmed [41]. The association that is found between the density of these predominantly immune related proteins in serum and clinical pain severity in JIA patients, could reflect inflammatory and immune components of pain in JIA. Furthermore, five proteins (IGHV3.9, PRG4, VWF, ALB and CST3) were significantly associated with ESR values, with CST3, a protein active in neurodegenerative (Alzheimer's Disease) and demyelinating (multiple sclerosis) neurological conditions [42]. ESR values obtained from blood samples reflect overall inflammatory status, and do not capture isolated joint inflammation. Thus, biological samples derived from the synovial compartment of inflamed joints may better identify proteomic markers that are more closely associated with joint inflammation and inflammatory pain.

The current sample consisted of patients who were in remission, reported pain without joint inflammation or reported pain with joint inflammation, where inflammatory status and other joint-related pathology was determined via musculoskeletal MRI. Moreover, our study confirms that pain in JIA is not always commensurate with the amount of inflammation, and also, subsets of proteins were solely associated with inflammation, but not pain. While confirmation in larger studies is necessary, we hypothesize that expression of some proteins is driven by pain and likely associated with peripheral or central sensitization, and other proteins will track more with the inflammatory status of JIA patient or JIA subtype.
A finer assessment of Pain-associated proteins in JIA is arguably obtained by differentiating patients based on additional diagnostic criteria, which include, JIA subtype (e.g., polyarticular JIA vs. systemic JIA), rheumatoid factor (RF) status, or antinuclear antibody (ANA) status as each can be associated with distinct JIA disease trajectories or severity [43]. A more specific, phenotypic differentiation of JIA patients may elucidate differential proteins expression of proteins in conjunction with distinct sets of Pain-associated proteins. Likewise, comparison of patients based on treatment regimen (e.g., methotrexate vs. methotrexate + TNF- $\alpha$ inhibitor) may also yield unique proteomic signatures. Although this pilot cohort varied in terms of JIA subtype, RF and ANA status, or treatment type the limited sample size did not allow for a robust comparison across these domains. Future work will investigate the contribution of these JIA subtypes and phenotypes in a broader population and importantly include clinical control groups. The incorporation of control cohorts is essential in order to decipher whether proteomic alterations are disease specific for JIA or pain specific.

Previous work aimed to gain more insight into the proteomic underpinnings of pain by performing a metaanalysis of 535 pain related genes in the human cerebrospinal fluid (CSF) [44]. These genes are typically responsible for proteins related to synaptic transmission, inflammatory responses, neuropeptide signaling, and hormonal activity. Furthermore, this study pointed to ten proteins that were potential factors for distinguishing dysfunctional (fibromyalgia) from inflammatory pain (rheumatoid arthritis) disorders. Although proteomic composition in the CSF will differ from blood serum, both tissues can be used to identify Pain-associated proteins. Considering the age of the cohort of JIA patients in this study, retrieving CSF samples was not feasible for ethical reasons. Serum protease network behavior in complex regional pain syndrome (CRPS) has also been recently investigated $[45,46]$. Here, relative to controls and other clinical pain populations, CRPS patients showed distinct degradation activity of inflammatory mediators that likely play a role in the development of post-traumatic pain. Konig and colleagues have specifically suggested that degradation of dabsyl-bradykinin is particularly compromised in CRPS, which subsequently drives an inflammatory process.

In prior work, JIA patients were shown to harbor altered CNS properties. Specifically, caudate nucleus volume was negatively correlated to clinical pain intensity and decreased cortical thickness of the insula was not only observed to be lower in JIA patients relative to controls, but also showed a negative correlation with ESR values [27]. Besides a role of the caudate nucleus in the motor system, it has also been proposed to play an 
important part in modulation of pain experience [47]. The insula, a key hub of the salience networks, plays an essential role in the regulation of emotional aspects of pain [48]. Correlations between both left and right caudate nucleus volume and some of the proteins were observed, and HRG was associated with caudate nucleus volume bilaterally and with right insular thickness. Left insular thickness did not correlate with any of the identified pain related protein densities, whilst right insular thickness was associated with three of the proteins, BTD, LGALS3BP and HRG. The associations of morphological properties and pain related proteins points to an interplay between peripheral mechanisms and the CNS. Pain in JIA is multifaceted and could be underpinned by altered proteomic composition contributing to pain and altered neurobiological properties to the emotional mediation of this pain.

With the novelty of this investigation into proteomic alterations concerning pain in JIA, limitations of this exploratory study are noted. Mainly, the small sample size was a limiting factor in this investigation yet provides a basis for extending this work into a larger patient sample. Also, all patients were on active treatment during study evaluation, and treatment plans varied from single immune-modulatory agents (i.e., methotrexate or adalimumab) to combination therapies (i.e., methotrexate and adalimumab). Moreover, some patients also noted intermittent use of non-steroidal anti-inflammatory drugs (e.g., naproxen). The type of therapy could have impacted the serum proteomic composition, particularly in specific immune-related proteins in the collected serum. In order to determine the influence of various therapies on the JIA proteome, future studies should characterize protein expression before and after treatment or before and after the onset of a new therapeutic regimen. Characterization of the proteome at multiple points post-treatment induction may also provide new biological insights towards treatment response vs. non-response.

\section{Conclusions}

In summary, LC/MS-based serum proteomic analysis identified 14 Pain-associated proteins in the serum of JIA patients. A number of the identified proteins had functional roles in immune or inflammatory processes. This investigation provides novel insights into deviations in the proteome in relation to clinical pain in JIA patients, and could contribute to the ongoing search for prognostic markers and treatment targets for JIA pain.

\section{Abbreviations}

Al: Anterior insula; ANA: antinuclear antibodies; BCH: Boston Children's Hospital; BiP: binding immunoglobulin protein; CJADAS: Clinical Juvenile Disease Activity Score; CNS: Central nervous system; CSF: cerebrospinal fluid; DMARDs: Disease-modifying anti-rheumatic drugs; ESR: Erythrocyte sedimentation rate; fMRI: Functional magnetic resonance imaging; IL: interleukin; JIA: Juvenile idiopathic arthritis; LC: liquied chromatography; MRI: magnetic resonance imaging; MS: mass spectrometry; MIF: macrophage inhibitory factor; PROMIS: Patient-Reported Outcomes Measurement Information System; RF: rheumatoid factor; SD: Standard deviation; RA: Rheumatoid arthritis; RF: Rheumatoid factor; TNF-a: Tumor Necrosis Factor-a

\section{Supplementary Information}

The online version contains supplementary material available at https://doi. org/10.1186/s12969-022-00662-1.

\section{Additional file 1}

\section{Acknowledgements}

Not applicable.

\section{Authors' contributions}

$J U, H S, R P S, P A N, K E$, and LAH designed the study. JU, RPS, DS, KH, and MT, collected data. RPS, JL, MMH, OH, EM, LAH, MHC, and PAN provided clinical oversight of individual JIA patients and completed clinical assessments. $\mathrm{HvdH}, \mathrm{BF}, \mathrm{KC}, J \mathrm{~L}, \mathrm{MC}, \mathrm{BG}, \mathrm{RS}, \mathrm{CJ}, \mathrm{KE}, \mathrm{LAH}, \mathrm{MHC}, \mathrm{HS}$, and JU performed data analysis and data interpretation. $\mathrm{HVDH}, \mathrm{BF}, \mathrm{KC}, \mathrm{RS}, \mathrm{HS}$, JU drafted the manuscript. All authors reviewed and provided input on the final draft of the manuscript. The author(s) read and approved the final manuscript.

\section{Authors' information}

Van Der Heijden, Hanne; Department of Anesthesiology, Critical Care and Pain Medicine, Boston Children's Hospital, Harvard Medical School; Maastricht University.

Fatou, Benoit; Department of Pathology, Boston Children's Hospital, Harvard Medical School.

Sibai, Diana; Department of Anesthesiology, Critical Care and Pain Medicine, Boston Children's Hospital, Harvard Medical School.

Hoyt, Kacie; Division of Immunology, Boston Children's Hospital, Harvard Medical School.

Taylor, Maria; Division of Immunology, Boston Children's Hospital, Harvard Medical School.

Cheung, Kin; BioSAS Consulting Inc.

Lemme, Jordan; Department of Anesthesiology, Critical Care and Pain Medicine, Boston Children's Hospital, Harvard Medical School.

Cay, Mariesa; Department of Anesthesiology, Critical Care and Pain Medicine, Boston Children's Hospital, Harvard Medical School.

Goodlett, Benjamin; Division of Genetics and Genomics, Boston Children's Hospital, Harvard Medical School.

Lo, Jeffery; Division of Immunology, Boston Children's Hospital, Harvard Medical School.

Hazen, Melissa M.; Division of Immunology, Boston Children's Hospital, Harvard Medical School.

Halyabar, Olha; Division of Immunology, Boston Children's Hospital, Harvard Medical School.

Meidan, Esra; Division of Immunology, Boston Children's Hospital, Harvard

Medical School.

Schreiber, Rudy; Maastricht University.

Jaimes, Camilo; Department of Radiology, Boston Children's Hospital, Harvard Medical School.

Ecklund, Kirsten; Department of Radiology, Boston Children's Hospital, Harvard Medical School.

Henderson, Lauren A.; Division of Immunology, Boston Children's Hospital, Harvard Medical School.

Chang, Margaret H.; Division of Immunology, Boston Children's Hospital, Harvard Medical School.

Nigrovic, Peter A.; Division of Immunology, Boston Children's Hospital, Harvard Medical School.

Sundel, Robert P.; Division of Immunology, Boston Children's Hospital, Harvard Medical School.

Steen, Hanno; Department of Pathology; Boston Children's Hospital, Harvard Medical School, 
Upadhyay, Jaymin; Department of Anesthesiology, Critical Care and Pain Medicine, Boston Children's Hospital, Harvard Medical School; Department of Psychiatry, McLean Hospital, Harvard Medical Schoo

\section{Funding}

This study was supported by the Peter Lehner Family Fund/Fred S. Rosen Chair in Pediatric Rheumatology, the Boston Children's Hospital CHMC Anesthesia Foundation, the Samara Jan Turkel Clinical Center for Pediatric Autoimmune Diseases. JU receives supported from the MAYDAY Fund, Orphan Disease Center Grant Program, and RF1 MH122967-01. PAN is supported by NIH grant 2P30AR070253.

\section{Availability of data and materials}

Data are available from the corresponding authors upon reasonable request and with permission of all sites contributing data.

\section{Declarations}

\section{Ethical approval and consent to participate}

This study was approved by the Boston Children's Hospital, Institutional Review Board (IRB-A00028741-7). All patients provided assent to participate in this study, while consent was provided by the patient's parent or legal guardian.

\section{Consent for publication}

Not applicable.

\section{Competing interests}

All authors declare no competing interest.

\section{Author details}

'Department of Anesthesiology, Critical Care and Pain Medicine, Boston Children's Hospital, Harvard Medical School, Boston, MA, USA. ${ }^{2}$ Faculty of Psychology and Neuroscience, Section Neuropsychology \&

Psychopharmacology Maastricht University, Maastricht, The Netherlands. ${ }^{3}$ Faculty of Science, Biomedical Sciences Neurobiology, University of Amsterdam, Amsterdam, The Netherlands. ${ }^{4}$ Department of Pathology, Boston Children's Hospital, Harvard Medical School, Boston, MA, USA. ${ }^{5}$ Division of Immunology, Boston Children's Hospital, Harvard Medical School, Boston, MA, USA. 'BioSAS Consulting, Inc, Wellesley, MA, USA. ${ }^{7}$ Division of Genetics and Genomics, Boston Children's Hospital, Harvard Medical School, Boston, MA, USA. ${ }^{8}$ Department of Radiology, Boston Children's Hospital, Harvard Medical School, Boston, MA, USA. ${ }^{9}$ Neurobiology Program, Boston Children's Hospital, Boston, MA, USA. ${ }^{10}$ Precision Vaccines Program, Boston Children's Hospital, Boston, MA, USA. "'Department of Psychiatry, McLean Hospital, Harvard Medical School, MA, Belmont, USA.

Received: 16 November 2021 Accepted: 1 January 2022

Published online: 15 January 2022

\section{References}

1. Petty RE, Southwood TR, Manners P, Baum J, Glass DN, Goldenberg J, et al. International league of associations for rheumatology classification of juvenile idiopathic arthritis: second revision, Edmonton, 2001. J Rheumatol. 2004;31(2):390-2.

2. Prakken B, Albani S, Martini A. Juvenile idiopathic arthritis. Lancet Lond Engl. 2011;377(9783):2138-49. https://doi.org/10.1016/S0140-6736(11)60244-4.

3. Tollisen A, Selvaag AM, Aulie HA, Lilleby V, Aasland A, Lerdal A, et al. Physical functioning, pain, and health-related quality of life in adults with juvenile idiopathic arthritis: a longitudinal 30-year Followup study. Arthritis Care Res. 2018;70(5):741-9. https://doi.org/10.1002/acr.23327.

4. Barth S, Haas J-P, Schlichtiger J, Molz J, Bisdorff B, Michels H, et al. Longterm health-related quality of life in German patients with juvenile idiopathic arthritis in comparison to German general population. PLoS One. 2016;11(4):e0153267. https://doi.org/10.1371/journal.pone.0153267.

5. Rebane K, Orenius T, Ristolainen L, Relas H, Kautiainen $H$, Luosujärvi R, et al. Pain interference and associated factors in young adults with juvenile idiopathic arthritis. Scand J Rheumatol. 2019;48(5):408-14. https://doi.org/1 0.1080/03009742.2019.1596308.
6. La Hausse de Lalouvière L, loannou Y, Fitzgerald M. Neural mechanisms underlying the pain of juvenile idiopathic arthritis. Nat Rev Rheumatol. 2014; 10(4):205-11. https://doi.org/10.1038/nrrheum.2014.4.

7. Schanberg LE, Anthony KK, Gil KM, Maurin EC. Daily pain and symptoms in children with polyarticular arthritis. Arthritis Rheum. 2003;48(5):1390-7. https://doi.org/10.1002/art.10986.

8. Vanoni F, Minoia F, Malattia C. Biologics in juvenile idiopathic arthritis: a narrative review. Eur J Pediatr. 2017;176(9):1147-53. https://doi.org/10.1007/ s00431-017-2960-6.

9. Giancane G, Consolaro A, Lanni S, Davì S, Schiappapietra B, Ravelli A. Juvenile idiopathic arthritis: diagnosis and treatment. Rheumatol Ther. 2016; 3(2):187-207. https://doi.org/10.1007/s40744-016-0040-4.

10. Weiss JE, Luca NJC, Boneparth A, Stinson J. Assessment and management of pain in juvenile idiopathic arthritis. Paediatr Drugs. 2014;16(6):473-81. https://doi.org/10.1007/s40272-014-0094-0.

11. Rashid A, Cordingley L, Carrasco R, Foster HE, Baildam EM, Chieng A, et al. Patterns of pain over time among children with juvenile idiopathic arthritis. Arch Dis Child. 2018;103(5):437-43. https://doi.org/10.1136/archdischild-201 7-313337.

12. Tarakci E, Yeldan I, Kaya Mutlu E, Baydogan SN, Kasapcopur O. The relationship between physical activity level, anxiety, depression, and functional ability in children and adolescents with juvenile idiopathic arthritis. Clin Rheumatol. 2011;30(11):1415-20. https://doi.org/10.1007/s1 0067-011-1832-0.

13. Morgan EM, Mara CA, Huang B, Barnett K, Carle AC, Farrell JE, et al. Establishing clinical meaning and defining important differences for patientreported outcomes measurement information system (PROMIS ${ }^{\circledR}$ ) measures in juvenile idiopathic arthritis using standard setting with patients, parents, and providers. Qual Life Res Int J Qual Life Asp Treat Care Rehabil. 2017; 26(3):565-86. https://doi.org/10.1007/s11136-016-1468-2.

14. Rochette E, Duché $P$, Merlin E. Juvenile idiopathic arthritis and physical activity: possible inflammatory and immune modulation and tracks for interventions in young populations. Autoimmun Rev. 2015;14(8):726-34. https://doi.org/10.1016/j.autrev.2015.04.007.

15. Lotito APN, Campa A, Silva CAA, Kiss MHB, Mello SBV. Interleukin 18 as a marker of disease activity and severity in patients with juvenile idiopathic arthritis. J Rheumatol. 2007;34(4):823-30.

16. de Jager W, Hoppenreijs EPAH, Wulffraat NM, Wedderburn LR, Kuis W Prakken BJ. Blood and synovial fluid cytokine signatures in patients with juvenile idiopathic arthritis: a cross-sectional study. Ann Rheum Dis. 2007; 66(5):589-98. https://doi.org/10.1136/ard.2006.061853.

17. Lin Y-T, Wang C-T, Gershwin ME, Chiang B-L. The pathogenesis of oligoarticular/polyarticular vs systemic juvenile idiopathic arthritis. Autoimmun Rev. 2011;10(8):482-9. https://doi.org/10.1016/j.autrev.2011.02.001.

18. Duurland $\mathrm{CL}$, Wedderburn LR. Current developments in the use of biomarkers for juvenile idiopathic arthritis. Curr Rheumatol Rep. 2014;16(3): 406. https://doi.org/10.1007/s11926-013-0406-3.

19. Husi H, Albalat A. Handbook of Pharmacogenomics and Stratified Medicine. Vols 147-179. 2014

20. Aebersold R, Mann M. Mass spectrometry-based proteomics. Nature. 2003; 422(6928):198-207. https://doi.org/10.1038/nature01511.

21. Domon B, Aebersold R. Mass spectrometry and protein analysis. Science. 2006;312(5771):212-7. https://doi.org/10.1126/science.1124619.

22. Gomez-Varela D, Barry AM, Schmidt M. Proteome-based systems biology in chronic pain. J Proteome. 2019;190:1-11. https://doi.org/10.1016/j.jprot.2018. 04.004.

23. Khoonsari PE, Ossipova E, Lengqvist J, Svensson Cl, Kosek E, Kadetoff D, et al. The human CSF pain proteome. J Proteome. 2019;190:67-76. https:// doi.org/10.1016/j.jprot.2018.05.012.

24. Ling XB, Park JL, Carroll T, Nguyen KD, Lau K, Macaubas C, et al. Plasma profiles in active systemic juvenile idiopathic arthritis: biomarkers and biological implications. Proteomics. 2010;10(24):4415-30. https://doi.org/10.1 002/pmic.201000298.

25. Brescia AC, Simonds MM, Sullivan KE, Rose CD. Secretion of proinflammatory cytokines and chemokines and loss of regulatory signals by fibroblast-like synoviocytes in juvenile idiopathic arthritis. Proteomics Clin Appl. 2017;11(5-6).

26. McErlane F, Beresford MW, Baildam EM, et al. Validity of a three-variable juvenile arthritis disease activity score in children with new-onset juvenile idiopathic arthritis. Ann Rheum Dis. 2013;72(12):1983-8. https://doi.org/1 0.1136/annrheumdis-2012-202031. 
27. Upadhyay J, Lemme J, Cay M, Van Der Heijden H, Sibai D, Goodlett B, et al. A multidisciplinary assessment of pain in juvenile idiopathic arthritis. Semin Arthritis Rheum. 2021;51(4):700-11. https://doi.org/10.1016/j.semarthrit.2021.05.011.

28. Hughes CS, Foehr S, Garfield DA, Furlong EE, Steinmetz LM, Krijgsveld J. Ultrasensitive proteome analysis using paramagnetic bead technology. Mol Syst Biol. 2014:10(10):757. https://doi.org/10.15252/msb.20145625.

29. Struyf S, Burdick MD, Proost P, Van Damme J, Strieter RM. Platelets release CXCL4L1, a nonallelic variant of the chemokine platelet factor-4/CXCL4 and potent inhibitor of angiogenesis. Circ Res. 2004;95(9):855-7. https://doi.org/1 0.1161/01.RES.0000146674.38319.07.

30. Raoof R, Willemen HLDM, Eijkelkamp N. Divergent roles of immune cells and their mediators in pain. Rheumatol Oxf Engl. 2018;57(3):429-40. https:// doi.org/10.1093/rheumatology/kex308.

31. Läubli H, Alisson-Silva F, Stanczak MA, Siddiqui SS, Deng L, Verhagen A, et al. Lectin galactoside-binding soluble 3 binding protein (LGALS3BP) is a tumor-associated immunomodulatory ligand for CD33-related Siglecs. J Biol Chem. 2014;289(48):33481-91. https://doi.org/10.1074/jbc.M114.593129.

32. Ohshima S, Kuchen S, Seemayer CA, Kyburz D, Hirt A, Klinzing S, et al. Galectin 3 and its binding protein in rheumatoid arthritis. Arthritis Rheum. 2003;48(10):2788-95. https://doi.org/10.1002/art.11287.

33. Kazeeva TN, Shevelev AB. Unknown functions of immunoglobulins a. Biochem Biokhimiia. 2007;72(5):485-94. https://doi.org/10.1134/S00062 97907050045

34. Kirkham B, Chaabo K, Hall C, Garrood T, Mant T, Allen E, et al. Safety and patient response as indicated by biomarker changes to binding immunoglobulin protein in the phase I/IIA RAGULA clinical trial in rheumatoid arthritis. Rheumatol Oxf Engl. 2016;55(11):1993-2000. https://doi. org/10.1093/rheumatology/kew287.

35. Staun-Ram E, Miller A. Cathepsins ( $\mathrm{S}$ and $\mathrm{B}$ ) and their inhibitor cystatin $\mathrm{C}$ in immune cells: modulation by interferon- $\beta$ and role played in cell migration. J Neuroimmunol. 2011;232(1-2):200-6. https://doi.org/10.1016/j.jneuroim.2 010.10.015.

36. Hooper LV, Stappenbeck TS, Hong CV, Gordon Jl. Angiogenins: a new class of microbicidal proteins involved in innate immunity. Nat Immunol. 2003; 4(3):269-73. https://doi.org/10.1038/ni888.

37. Lee SH, Kim KW, Min K-M, Kim K-W, Chang S-I, Kim JC. Angiogenin reduces immune inflammation via inhibition of TANK-binding kinase 1 expression in human corneal fibroblast cells. Mediat Inflamm. 2014:2014:861435-12. https://doi.org/10.1155/2014/861435.

38. Lioté F, Champy R, Moenner M, Boval-Boizard B, Badet J. Elevated angiogenin levels in synovial fluid from patients with inflammatory arthritis and secretion of angiogenin by cultured synovial fibroblasts. Clin Exp Immunol. 2003;132(1): 163-8. https://doi.org/10.1046/j.1365-2249.2003.02117.x.

39. Gragnano F, Sperlongano S, Golia E, Natale F, Bianchi R, Crisci M, et al. The role of von Willebrand factor in vascular inflammation: from pathogenesis to targeted therapy. Mediat Inflamm. 2017;2017:5620314-3. https://doi.org/1 $0.1155 / 2017 / 5620314$.

40. Novince CM, Koh AJ, Michalski MN, Marchesan JT, Wang J, Jung Y, et al. Proteoglycan 4, a novel immunomodulatory factor, regulates parathyroid hormone actions on hematopoietic cells. Am J Pathol. 2011;179(5):2431-42. https://doi.org/10.1016/j.ajpath.2011.07.032.

41. Alquraini A, Garguilo S, D'Souza G, Zhang LX, Schmidt TA, Jay GD, et al. The interaction of lubricin/proteoglycan 4 (PRG4) with toll-like receptors 2 and 4 : an anti-inflammatory role of PRG4 in synovial fluid. Arthritis Res Ther. 2015; 17(1):353. https://doi.org/10.1186/s13075-015-0877-x.

42. Maniwa K, Yano S, Sheikh AM, Onoda K, Mitaki S, Isomura M, et al. Association between cystatin $\mathrm{C}$ gene polymorphism and the prevalence of white matter lesion in elderly healthy subjects. Sci Rep. 2020;10(1):4688. https://doi.org/10.1038/s41598-020-61383-7.

43. Hügle B, Hinze C, Lainka E, Fischer N, Haas J-P. Development of positive antinuclear antibodies and rheumatoid factor in systemic juvenile idiopathic arthritis points toward an autoimmune phenotype later in the disease course. Pediatr Rheumatol Online J. 2014;12(1):28. https://doi.org/10.1186/1 546-0096-12-28

44. Ultsch A, Kringel D, Kalso E, Mogil JS, Lötsch J. A data science approach to candidate gene selection of pain regarded as a process of learning and neural plasticity. Pain. 2016;157(12):2747-57. https://doi.org/10.1097/j.pain. 0000000000000694.

45. König S, Bayer M, Dimova V, Herrnberger M, Escolano-Lozano F, Bednarik J, et al. The serum protease network-one key to understand complex regional pain syndrome pathophysiology. Pain. 2019;160(6):1402-9. https://doi.org/1 0.1097/j.pain.0000000000001503.

46. König S, Schlereth T, Birklein F. Molecular signature of complex regional pain syndrome (CRPS) and its analysis. Expert Rev Proteomics. 2017;14(10): 857-67. https://doi.org/10.1080/14789450.2017.1366859.

47. Wunderlich AP, Klug R, Stuber G, Landwehrmeyer B, Weber F, Freund W. Caudate nucleus and insular activation during a pain suppression paradigm comparing thermal and electrical stimulation. Open Neuroimaging J. 2011;5: 1-8. https://doi.org/10.2174/1874440001105010001.

48. Craig ADB. How do you feel--now? The anterior insula and human awareness. Nat Rev Neurosci. 2009;10(1):59-70. https://doi.org/10.1038/nrn2555.

\section{Publisher's Note}

Springer Nature remains neutral with regard to jurisdictional claims in published maps and institutional affiliations.
Ready to submit your research? Choose BMC and benefit from:

- fast, convenient online submission

- thorough peer review by experienced researchers in your field

- rapid publication on acceptance

- support for research data, including large and complex data types

- gold Open Access which fosters wider collaboration and increased citations

- maximum visibility for your research: over $100 \mathrm{M}$ website views per year

At BMC, research is always in progress.

Learn more biomedcentral.com/submissions 